\title{
A Study on the Improvement Plan for Effectiveness of Disaster Management Training and Exercise
}

\author{
Se-Ryeun Park ${ }^{1}$, and Hong-Sik Yun ${ }^{2}$
}

\begin{abstract}
In this study, in order to improve the effectiveness of disaster management training and exercise, did investigate the current disaster management training and exercise program for local government officials who is currently in charge of the disaster management tasks. Based on the results of the analysis, propose methods to improve the effectiveness. Local governments are the primary responsibility for disaster response. Local governments that are obliged to protect people's lives and properties when a disaster occurs should strengthen disaster management capabilities to prevent disasters and minimize damages. In order to increase the effectiveness of disaster management training and exercise, this study propose legislation on disaster management training and exercise, and suggest to use both of discussion-based training and exercise methods and operational-based training and exercise methods and to complete a course of disaster education programmes for changing local governments officials recognition.
\end{abstract}

Keywords-Disaster Management, Local Government, Disaster Safety, Training and Exercise.

\section{INTRODUCTION}

As the size and frequency of disasters increases around the world, the awareness of the importance of disaster management is increasing. The types of social disasters that can be caused by industrialization and urbanization have become more diverse, and the likelihood of natural disasters has increased due to climate change. The nation should make efforts to prevent and prepare for disasters in order to minimize the loss of life and property when a disaster occurs.

The April ferry disaster occurred in 2014, which showed that the disaster management of Korea was insufficient. With the April ferry disaster, the central and local governments became aware of the importance of the initial response. Since the disaster occurs locally, the role of the local government in the initial response is very important.

In order to enhance the disaster management capacity of local governments, disaster management training and exercise is being conducted for local government officials who is currently in charge of the disaster management tasks. However, it is

\footnotetext{
${ }^{1}$ Master's Course, Department of Disaster Prevention Safety Engineering Cooperation Course, SungKyunKwan Univ., 2066, Seobu-ro, Jangan-gu, Suwon, Korea / email: psr9308@ naver.com

${ }^{2}$ Professor, Department of Disaster Prevention Safety Engineering Cooperation Course, SungKyunKwan Univ., 2066, Seobu-ro, Jangan-gu, Suwon, Korea / email: yoonhs@skku.edu.
}

necessary to confirm whether the current disaster management training and exercise is effective in enhancing the disaster management capacity of local governments and whether there is any improvement in order to improve the effectiveness.

The purpose of this study is to identify and improve the effectiveness of disaster management training and exercise for disaster management officers in local governments. For this, we analyzed the previous research and the present situation and current situation of disaster management training and exercise. Based on the results of the analysis, we'd confirm the effectiveness of disaster management training and exercise and suggest ways of improvement.

\section{THEORETICAL BACKGROUND}

\section{A. Concept of Disaster and Disaster Management}

The definition of disaster and disaster management differs from one scholar to another, but according to Article 3 of Misfortune and the safety supervision basic law, "Disaster" means something that can damage life, physical and property of the people and the nation, a. Natural disasters: Typhoons, floods, heavy rain, strong winds, storms, tsunami, heavy snowfalls, lighting, droughts, earthquakes, yellow dust, algal blooms, tidal water, volcanic activity, other disasters caused by other natural phenomena, b. Social disaster: damage caused by fire, collapse, explosion, traffic accidents(including air accidents and coast accidents), NBC accidents, environmental pollution accidents, etc., and energy, communications, traffic, finance, medical care, infectious diseases in accordance with the Act on the prevention and management of infectious diseases, or the spread of livestock infectious diseases caused by the livestock infectious diseases prevention Act.

In Article 3 of the Act, "disaster management" is defined as all activities for preventing, preparing, responding and recovering from a disaster. In addition, Article 4(1) of the Misfortune and the safety supervision basic law states that "the state and local governments have the responsibility to protect the lives, physical and property of the people from disasters and other accidents and to prevent disasters and other accidents, and establish and Implement a plan to promptly respond to and recover from the damage that has occurred."

Disaster management means that the four phases of prevention, preparation, response, and recovery are common to the central and local governments, and that the integrated 
mechanisms for sequential and total management are organized and managed in four stages (Sang-hyun Joo, 2007).

\section{B. Characteristics of disaster and disaster management}

Disaster has been discussed as having properties such as uncertainty, complexity, cumulative, and cognitive characteristics (Young-geun Hong, 2012). According to the Young-geun Hong(2012), first, disaster has uncertainty. The scale and extent of losses from disasters due to the limitations of future forecasts is uncertain. Second, disasters are complicated in the complexity of the disaster itself and in the relationships between agencies involved in disaster management. Third, disaster is characterized by accumulation in that it occurs due to the ignorance of the risk factors accumulated before the occurrence, improper information, miscommunication, and failure to comply with safety regulations. Fourth, disaster has cognitive characteristics. The ambiguity in language expressing the disaster situation is accumulating as a factor of future disaster by restricting or obstructing the collection and communication of disaster related information.

Ho-Joon Choi, and Sang-il Ryu(2006) point out that disaster management at the level of local government has the following characteristics: First, local disaster occurs narrowly in a spatially constant area but strong. Second, it is noted that regional disasters tend to occur periodically and repeatedly. Third, because of the geographical and natural characteristics and industrial characteristics of a specific region, the regional disaster response system should be constructed and operated differently in the different types of disasters in each region. Geon-ju Kwon(2012) suggested that local governments play the following important role in effective management of disaster. First, local governments play a leading role in directly implementing the entire life cycle of the disaster (prevention/mitigation, protection, response, recovery). Second, local governments coordinate the various agencies, groups and stakeholders involved in the disaster management process. In particular, in the event of a disaster, when many human and material resources are put in at once, efficient and effective allocation and utilization of resources and consultation and coordination of roles should be planned.

\section{Significance of disaster management training and exercise}

In South Korea, the National Disaster Management Institute under the National Emergency Management was established in 2006 to carry out special education in the field of disaster management after the enactment of the Basic Law on Misfortune and the safety supervision. At the time of establishment, the training course for general civil defense life safety and disaster prevention education was opened. The aim was to train experts of disaster mitigation activities to protect the lives and property of the people from various disasters. In 2012, the National Disaster Management Institute has been renamed the Central Civil Defense and Disaster Management Institute to provide training on human disaster, natural disaster, and civil defense field (Ji-hwan Park, Yoon-hee Kim, 2014).

The ability of an Disaster Management organization to respond to disasters is best assessed through actual disasters. However, it is impractical and uneconomic to assess response capabilities through actual responses to disasters. In addition, there is a disadvantage that it is impossible to quickly identify the vulnerable parts of emergency rescue agencies and disaster response systems, and to quickly correct the parts that need to be revised in the response plan (Gi-bong Go, Si-young Lee, Jin Chae, 2010). According to Gi-bong Go, Si-young Lee, Jin Chae(2010), disaster response organizations need to assess disaster response capability through regular disaster response training, to constantly revise and complement the response plan, and to strengthen cooperation with support organizations. In other words, disaster response training is one of the most effective ways to improve the ability of all agencies, organizations, and workers involved in disaster management and test the effectiveness of disaster response systems.

The effects of training and exercise not only mean the knowledge and skills acquired by the trainee through education and training, but also include many aspects such as the attitude of the trainee or recognition of the work. In addition, the effect of education and training on the overall education and training of the trainee can be extended to the organization by utilizing and expressing the skills and knowledge in their organizations (Roe-ho Kim, Yong-su Kwon, Hae-young Kim, 2014).

Training and exercise in the disaster management field mainly apply a gradual training and exercise method. Training and exercise methods include Discussion-based training and exercise method such as seminars, workshops, on-the-road training and games, and Operational-based training and exercise method consisting of drill, functional exercises, actual training(Ji-hwan Park, Yoon-hee Kim, 2014). According to Ji-hwan Park, Yoon-hee Kim(2014), this approach is based on the ability of organizations to implement disaster management training and exercise, It has the advantage that it can be applied variously.

In disaster management, the formation of a close relationship and a continuous network with relevant organizations is essential to respond quickly when disaster occurs. This is possible through systematic training and exercise before the disaster. The disaster management capacity of local governments will be enhanced if training and exercise are applied to the disaster management officers of local governments using the discussion-based training and exercise and the operation-based training and exercise as appropriate ratio.

\section{ANALYSIS}

\section{A. Concept of Disaster and Disaster Management}

Local governments, which are in charge of primary response in the event of a disaster, are conducting disaster education through the Central Civil Defense and Disaster Management Institute, the Provincial Office Education Center, and the Korea Local Autonomy Development Institute(Ji-hwan Park, Yoon-hee Kim, 2014). According to Ji-hwan Park, Yoon-hee Kim(2014), disaster management training and exercise in local 
governments is partly carried out by the Provincial Office Education Center, and the Korea Local Autonomy Development Institute, and most of them are in charge of training and exercise in the Central Civil Defense and Disaster Management Institute. According to data on the disaster management field in 6 the Provincial Office Education Center, human and natural disaster training is a large part and training in social disaster area is insufficient.

According to Ji-hwan Park, Yoon-hee Kim(2014), some local governments have less than $1 \%$ of disaster management training and exercise among all public official training and exercise, and some local governments lack sufficient courses. The 2013 plan shows that the number of courses and the number of participants are small, which means that the awareness of disaster management training and exercise is very low.

\section{B. Analysis of status and actual condition of disaster management training and exercise}

In the previous studies on the disaster management training and exercise, it was found that Ji-hwan Park, Yoon-hee $\operatorname{Kim}(2014)$ analyzed the problems of the disaster management training and exercise. The problems of the training and exercise itself are as follows. First, the quality of the lecture is poor and the work relation is low. Second, there is no evaluation method, the third is the problem of the lecture method, and the fourth is the problem of the lecture time. The problems of the organizational and environmental are as follow. First, difficulty in applying for enrollment in training and exercise due to heavy workload. Second, organizational atmosphere that does not encourage application for disaster management training and exercise. Third, lack of budget and place of disaster management training and exercise.

Some studies have analyzed the effectiveness of disaster management training and exercise. Roe-ho Kim, Yong-su Kwon, Hae-young Kim(2014) conducted a correlation analysis of training and exercise factors consisting of training and exercise contents, training and exercise methods, and organizational environment that influenced disaster management capacity. As a result of the analysis, it was confirmed that contents, method, and the organizational environment were positively related to public officials' perception of disaster management capacity that can be considered as the effect of training and exercise.

For effective disaster management, it is essential to strengthen disaster management capacity of local governments. In previous studies, it proved that training and exercise are effective in strengthening disaster management capacity of local governments. Currently, disaster management training and exercise program for local government officials who is currently in charge of the disaster management tasks are being conducted, but the effectiveness of training and exercise in raising disaster management capacity of local governments is low.

First of all, it is difficult to prove the effectiveness of training and exercise in that it is operated at discretion rather than obligations of local governments. Disasters occur locally, but it is difficult to predict the size and location of the disasters.
Therefore, in order to effectively respond to all disasters, close cooperation and rapid communication should be achieved from the jurisdiction to the relevant agencies, adjacent areas, and the central government. The disaster management capacity of local governments is the key in the event of a disaster requiring rapid judgment and organizational response. However, it is difficult to improve disaster management capacity because the proportion of disaster management training and exercise in local governments is different and the training and exercise curriculum is lacking.

The training and exercise methods currently implemented are also unlikely to increase the disaster management capacity of local governments. Most of the training is done by lecture and discussion, but the method of training is limited. Most local government officials who is currently in charge of the disaster management tasks are not experts in disaster management. It is possible to improve the disaster management capacity of local governments by allowing other serial officers to acquire expertise in the field of disaster management and to acquire their roles, responsibilities and duties in order to respond promptly in real situations. However, it is not effective to increase the disaster management capacity by only lecturing or discussing the training course.

Finally, there is low awareness of the need for disaster management training and exercise for local governments and public officials. Efforts to raise disaster management capacity are essential in local governments, which are the primary responsibility for disaster management. However, local governments do not have the necessity and the duty of training and exercise, and overlook the importance of training and exercise. Despite the difficulty in predicting when and where a disaster will occur, local governments that have not experienced a disaster within their jurisdiction often recognize disaster management as a secondary task. Local governments have low responsibility for disaster management as a disaster management agency. Therefore, the effectiveness of disaster education training seems to be low

\section{IMPROVING THE EFFECTIVENESS OF DISASTER TRAINING AND EXERCISE}

In this study, we analyzed the precedent studies and current situation in disaster management training and exercise and confirmed the effectiveness of disaster management training and exercise that is currently being conducted for local governments officers. The results of the analysis show that the disaster management training and exercise of local governments are operated according to the discretion of local governments and that the training and exercise method is very limited, And low awareness of the need for training and exercise.

This study suggests three ways to improve the effectiveness of disaster management training and exercise based on the analysis of current state of disaster management training and exercise. As a result of the analysis, the first problem was that disaster management training and exercise were operated according to the discretion of local governments. If the proportion of training and exercise is different for each local 
government and lack of training and exercise courses, it can be difficult when disasters that require close cooperation between local governments. In order to minimize these problems and increase the effectiveness of disaster management training and exercise, there is a plan to mandate training and exercise for disaster management officers in all local governments. The mandatory of systematic training and exercise programs to be completed in a reasonable amount of time would have the effect of increasing the capacity of disaster management in local governments and reducing the variation of disaster management capacity between regions.

The second problem is that the training method is very limited. The disaster management capacity of local governments is not raised by temporary education. It is necessary to receive training and exercise gradually according to systematic training and exercise stages, and to use various education methods. The ultimate goal of disaster management training and exercise is not simply delivering knowledge to disaster management officers, but allowing them to respond in real situations. Discussion-based training and exercise methods and operational-based training and exercise methods can be used to enhance the effectiveness of disaster management training and exercise.

As a result of analyzing the current status and actual conditions of disaster management training and exercise, it is also pointed out that the recognition of the need of disaster management training and exercise by local governments and officials in charge is low. Local governments are the first institutions to respond to disasters. Despite the increasing awareness of the importance of initial response due to repeated major disasters, local governments have not recognized the need for disaster management training and exercise. In order to be effective in training and exercise, awareness and attitude of receiving the training and exercise is very important. It is important to make disaster management training and exercise mandatory in the institutional aspect, but it is also important to change the perception of local government officials. If disaster management education programs for the recognition of local government officials are mandatory, ultimately, the effectiveness of disaster management training and exercise will be enhanced.

\section{CONCLUSION}

Many major disasters have led to the recognition of the importance of initial response in disaster management. When a disaster occurs, local governments in the affected area will respond first. In order for the initial response of a disaster to be successful, complex mechanisms such as quick judgment, cooperation with related institutions, and utilization of disaster resources should be organized organically. For this reason, disaster management capacity of local governments is an essential element in disaster management. Disaster management capabilities of local governments can be achieved through training and exercise. Currently, disaster management training and exercise is conducted for disaster management officers in local governments, but the effectiveness is very low.

This study analyzed the present status and actual situation of disaster management training and exercise in order to confirm the effectiveness of disaster management training and exercise for local government 's disaster management officers. The results of the analysis show that the disaster management training and exercise of local governments are operated according to the discretion of local governments and that the training and exercise method is very limited, And low awareness of the need for training and exercise. The results of the analysis show that the effectiveness of disaster management training and exercise is low.

This study suggests three ways to improve the effectiveness of disaster management training and exercise based on the analysis of current state and actual situation of disaster management training and exercise. The first effective improvement plan is the mandatory disaster management training and exercise in all local governments. The second effective improvement plan is to use both Discussion-based and Operational-based training methods in disaster management training and exercise. The final plan is to create a disaster management education program for the recognition of local governments and to make them compulsory.

The purpose of this study is to identify the effectiveness of disaster management training and exercise in order to improve the disaster management capacity of local governments and to suggest ways to enhance effectiveness. However, the limitations of this study are that it focuses on the analysis of existing researches in investigating and analyzing the current status and actual conditions of disaster safety education and training. In addition, the lack of research on disaster management training and exercise in advanced countries's disaster management is also a limitation of this study.

Prior studies on disaster management training and exercise in Republic of Korea are sufficient to recognize the importance of training and exercise. However, the methodological study of training and exercise is still insufficient. In the future, it will be necessary to study disaster management training and exercise methodology so that training and exercise can be effective.

\section{ACKNOWLEDGMENT}

This work is financially supported by Minister of Public Safety and Security as $\ulcorner$ BK21 Plus Creative Technology of Crisis, Disaster and Risk Management $\lrcorner$

\section{REFERENCES}

[1] Sang-hyun Joo, Gi-young Park. Development Plan of the Disaster Management Organization in Local Government. $\ulcorner$ The Korean Journal of Local Government Studies 」 . (2007). 11(3). 111-132

[2] Young-geun Hong(2012) A Study on Efficiency Improvement of Local Government Disaster Management.

[3] Ho-Joon Choi, and Sang-il Ryu. Plan for Improvement of Local Governments' Roles for Effective Countermeasures for Disasters -Centering on Comparison with USA and Japan -. Journal of the Korea Contents Association. (2006). 6(12). 235-243

[4] Geon-ju Kwon. A Study on Recognition of Education and Training for Tsunami : Focused on Sam-cheok Citizens. Crisis and Emergency Management. (2012). 8(1). 23-38

[5] Ji-hwan Park, Yoon-hee Kim. Overview and Issues of Disaster Management Training and Exercise Program for Local Government 
Officials. Journal of the Korea Contents Association. (2014). 14(11). $702-712$

[6] Gi-bong Go, Si-young Lee, Jin Chae. A Study on Disaster Management Officer's Perception about the Disaster Response Exercise - Focused on General Officers and Firemen. Fire Science and Engineering. (2010). 24(6). 34-44

[7] Roe-ho Kim, Yong-su Kwon, Hae-young Kim. A Study on the Improvement of the Effectiveness of Education and Training in Disaster Safety Management. Korean Society For Public Personnel Administration. (2014). 13(3). 385-401 